\title{
Análise do Projeto de Acompanhamento Pedagógico Diferenciado para Alunos com Dificuldades de Aprendizagem em leitura e escrita na rede pública de ensino estadual mineira
}

\author{
Andréia Maria Rodrigues Silva \\ Secretaria Estadual de Educação \\ Universidade Federal de Juiz de Fora \\ andreiasreunai@gmail.com \\ Laura Silveira Botelho \\ Universidade Federal de São João Del-Rei \\ laurabotelho@ufsj.edu.br
}

\section{Resumo}

Neste trabalho, discutimos sobre o projeto Acompanhamento Pedagógico Diferenciado (APD), que apoia estudantes do $4^{\circ}$ ao $9^{\circ}$ ano do Ensino Fundamental com dificuldades de aprendizagem nos processos de alfabetização. Como objetivo central, investigamos os desafios e as possibilidades do projeto APD com base na perspectiva dos professores envolvidos. Analisamos quais as possibilidades da intervenção pedagógica realizada pelo professor para Ensino do Uso de Biblioteca (Peub) junto aos alunos que apresentam dificuldades em leitura e escrita. Como referencial teórico, apoiamo-nos nos Estudos do Letramento (STREET, 2014) e na perspectiva de alfabetização e letramento proposta por Soares $(2004 ; 2018)$. A metodologia de pesquisa foi pautada em uma abordagem qualitativa interpretativista no viés da Linguística Aplicada, tendo como coleta de dados a realização de grupo focal com professores designados do projeto. Com base nos dados coletados, delimitamos quatro eixos de análise que nos permitiram conhecer a realidade do trabalho desenvolvido com alunos com dificuldades de leitura e escrita. Os resultados indicam a necessidade de ações na tentativa de contribuir com o desenvolvimento do projeto de modo que abarque formação continuada e planejada de acordo com as necessidades dos professores envolvidos no projeto. A análise também evidencia que a antecipação da intervenção pedagógica para os primeiros anos do Ensino Fundamental em articulação com o Programa Mais Alfabetização se faz necessária, além de ser imprescindível um trabalho de reaproximação da escola-família.

Palavras-chave: Alfabetização e letramento. Formação de professores de língua portuguesa. Dificuldades de aprendizagem. 
Alfabetização e letramento nos processos de ensino e aprendizagem...

\begin{abstract}
In this paper, we discuss the Differentiated Pedagogical Monitoring Project, which supports students from the 4th to the 9th grade of elementary school with learning difficulties in literacy processes. As a central objective, we investigate the challenges and possibilities of the project based on the perspective of the teachers involved. We analyzed the possibilities of the pedagogical intervention carried out by the teacher for Teaching for the Use of Library with students who have difficulties in reading and writing. As a theoretical framework, we rely on Literacy Studies (STREET, 2014) and on the perspective of reading and writing skills and literacy proposed by Soares $(2004 ; 2018)$. The research methodology was based on a qualitative interpretative approach in the Applied Linguistics perspective, having as data collection the creation of a focus group with teachers working on the project. Based on the data collected, we delineated four axes of analysis that allowed us to know the reality of the work developed with students with reading and writing difficulties. Results indicate the need for actions in an attempt to contribute to the development of the project so that it encompasses ongoing and planned training in accordance with the needs of the teachers involved. The analysis also shows that the anticipation of the pedagogical intervention for the first years of Elementary School in conjunction with the "Mais Alfabetização" Program (More Literacy Program) is necessary, in addition to the need to bring the school and family closer together.
\end{abstract}

Keywords: Reading and writing skills and literacy. Portuguese language teacher education. Learning disabilities.

\title{
1 Introdução
}

Este artigo $^{1}$ aborda as dificuldades de aprendizagem apresentadas por alunos do $4^{\circ}$ ao $9^{\circ}$ ano do Ensino Fundamental atendidos no projeto

${ }^{1} \mathrm{O}$ artigo foi elaborado com base na ampliação da análise da dissertação de Andréia Maria Rodrigues Silva, desenvolvida no Programa de Pós-Graduação de Gestão e Avaliação da Educação Pública, orientada pela Profa. Dra. Laura Silveira Botelho. Esse trabalho insere-se em um projeto de pesquisa mais amplo, desenvolvido no âmbito do grupo de pesquisa Letramentos, gêneros e ensino Legen/CNPQ, que investiga práticas de leitura e escrita na escola básica e no ensino superior. 
Acompanhamento Pedagógico Diferenciado ${ }^{2}$ (APD), uma ação da Secretaria Estadual de Educação de Minas Gerais. Na perspectiva do referido projeto, analisamos quais as possibilidades de uma intervenção pedagógica realizada pelo professor para Ensino do Uso de Biblioteca ${ }^{3}$ (doravante, Peub) junto a esses alunos que apresentam dificuldades em leitura e escrita.

Há muito se discutem os temas alfabetização e letramento ${ }^{4}$ no Brasil. Apesar das muitas pesquisas realizadas no campo da alfabetização, dos muitos métodos adotados nas últimas décadas, ainda nos deparamos com alunos que chegam aos anos finais do Ensino Fundamental sem estam alfabetizados. Embora haja avanços, somos um país que vem reincidindo no fracasso em alfabetização (SOARES, 2018).

Com base na perspectiva de que o desenvolvimento em leitura e escrita possibilita aos sujeitos uma formação crítica e cidadã, observamos que muitos alunos não conseguem se apropriar das habilidades inerentes ao processo de alfabetizar-se letrando.

De acordo com Soares (2004), tem-se atribuído um significado demasiado abrangente à alfabetização, considerando-a um processo permanente que não se esgota na aprendizagem do código. Ao considerarmos que a alfabetização é também um processo de compreensão/expressão de significados por meio do código escrito, corroboramos com o conceito proposto por Soares (2004) de que a alfabetização envolve um processo de representação de fonemas em grafemas e vice-versa, mas vai além disso, pois tal processo está vinculado às práticas sociais, ou seja, aos letramentos.

Com base em um viés da Linguística Aplicada com interesse em reflexões sobre formação docente, buscamos responder à seguinte questão de investigação: quais as possibilidades de o professor de Ensino e Uso de

${ }^{2} \mathrm{O}$ APD é um projeto desenvolvido pela Secretaria de Estado de Educação de Minas Gerais (SEE/MG). Consiste na seleção de algumas escolas que são contempladas para desenvolvê-lo com direito à contratação de um professor alfabetizador específico para trabalhar efetivamente com os alunos que apresentam dificuldades na aquisição inicial da leitura e da escrita.

${ }^{3}$ Professor designado para o trabalho nas bibliotecas escolares, na condução de ações e projetos voltados para a formação de leitores.

${ }^{4}$ Neste trabalho, decidimos usar o termo letramento tanto no singular como no plural. Em todos os usos a ideia de letramentos serem múltiplos está presente. 
Biblioteca (Peub) desenvolver, baseado na proposta do Projeto APD, uma intervenção pedagógica para os alunos que apresentam dificuldades de aprendizagem? Por conseguinte, o estudo tem como objetivo analisar os desafios e as possibilidades do projeto APD com base na perspectiva dos professores envolvidos.

Para cumprir esse objetivo e responder à questão proposta, organizamos este artigo com as seguintes etapas: inicialmente, apresentamos nossos pressupostos teóricos, amparados pelos estudos do letramento e a perspectiva de alfabetização e letramento proposta por Soares (2004; 2018) e Batista et al. (2005). Em seguida, discutimos algumas políticas educacionais de alfabetização e letramento estabelecidas e analisamos o projeto APD numa Superintendência Regional de Ensino do Estado de Minas Gerais. ${ }^{5}$ Essa etapa teve como finalidade gerar dados com os quais pudéssemos mapear e analisar os desafios e as perspectivas do Projeto APD com alunos do $4^{\circ}$ ao $9^{\circ}$ ano do Ensino Fundamental.

Dando continuidade à análise dos dados, como metodologia optamos pela abordagem qualitativa de pesquisa do estudo de caso. Para os instrumentos de coleta de dados foi realizado um grupo focal (GATTI, 2005) com os professores participantes da pesquisa, no qual buscamos identificar o desenvolvimento do projeto em questão. Assim, delimitamos quatro categorias de análise que serão abordadas mais à frente. Por fim, apresentamos nossas considerações finais.

\section{Alfabetização e letramento: articulando concepções e perspectivas no projeto APD}

Trazemos aqui uma breve retomada sobre a importância da escola no processo de alfabetização e de letramento embasados na corrente teórica dos Estudos de Letramento (STREET, 2014), além da reflexão sobre alfabetização na perspectiva de Soares $(2000 ; 2018)$.

Considerando a alfabetização como direito de todos, alinhamo-nos com Soares (2004) ao definir alfabetização como "ação de ensinar/aprender a ler e a escrever" e letramento como o "estado ou condição de quem não apenas sabe ler e escrever, mas cultiva e exerce as práticas sociais que

${ }^{5}$ Por motivos éticos, não vamos nomear a SRE. 
usam a escrita" (SOARES, 2004, p. 47). No entanto, a autora ressalta que apesar de serem processos distintos são, ao mesmo tempo, indissociáveis, o que nos leva a ter contato com muitos termos utilizados quando se trata dessa temática, tais como: alfabetizar letrando, alfabetização na perspectiva do letramento, letramento e alfabetização, letrar alfabetizando, dentre outros.

Na dimensão social, o letramento é visto como um fenômeno cultural, sobretudo uma prática social com a escrita em que os indivíduos se envolvem em seu contexto social, ao passo que na dimensão individual o letramento é tido no âmbito pessoal, mas que envolve dois processos diferentes: ler e escrever. Soares (1998) argumenta que, do ponto de vista da dimensão individual, a leitura é um conjunto de habilidades linguísticas que se estendem desde a habilidade de decodificar palavras escritas até a capacidade de compreender textos escritos, enquanto as habilidades de escrita se estendem da habilidade de registrar unidades de som até a capacidade de transmitir significado de forma adequada a um leitor potencial, sendo, assim, categorias complementares (SOARES, 1998, p. 69).

Nessa mesma perspectiva, Kleiman (1995) destaca a importância dos estudos de letramento tanto do interesse teórico quanto do social na busca da transformação de uma realidade que marginaliza grupos sociais que não conhecem a escrita.

Street (2014) esclarece que os letramentos são múltiplos e podem ser socialmente legitimados ou não. Nesse sentido, Soares (2010) enfatiza ainda que o termo letramento e suas implicações para as práticas sociais dos sujeitos vêm sofrendo ressignificações devido às mudanças sociais ocorridas nos últimos tempos. Tais ressignificações mostram, entre outros, que o papel da escola é ampliar os letramentos dos alunos para que estes possam desenvolver capacidades de leitura e escrita em diversos contextos sociais com vistas à participação ativa na sociedade. Consideramos essa concepção fundamental para esta pesquisa, pois é com base em tais reflexões que decidimos analisar o projeto APD na perspectiva dos professores envolvidos. Tal projeto busca contribuir para que alunos com dificuldades em leitura e escrita em anos avançados tenham um acompanhamento mais próximo, auxiliando na ampliação de seus letramentos. 
Logo, podemos observar que o letramento é entendido como uma ferramenta de valor social e cultural, de modo que dissociar a habilidade de leitura da de escrita de seus usos e finalidades se torna algo contraditório, pelo fato de a escolarização e o letramento ocorrerem de forma simultânea, até porque a escola é considerada uma das principais agências de letramento em muitas sociedades (KLEIMAN, 1995).

É importante ressaltar que o termo "letramento", no Brasil, se consolida como uma ferramenta teórica para se compreender um fenômeno cultural, os modos e as condições com que a sociedade brasileira lida com a escrita, mas também como pressuposto pedagógico e fundamento metodológico para o ensino da leitura e da escrita (MARINHO, 2010).

Com o início das discussões sobre o letramento, surge também a polêmica dos métodos e das propostas de retorno aos chamados "métodos tradicionais", resultando em embates e discussões sobre o fracasso da alfabetização, que seria causado por uma perda da especificidade da alfabetização na sua dimensão de aquisição e apropriação do sistema da língua escrita. Soares (2004) nomeou esse momento histórico como a invenção do letramento, a "desinvenção" da alfabetização e a tentativa de reinvenção da alfabetização.

Com base nesses conceitos são alicerçados os pressupostos do projeto APD, que objetivam desenvolver as habilidades de leitura e escrita de alunos que não tiveram a oportunidade de desenvolvê-las na idade adequada.

\section{Políticas públicas educacionais: implicações nos processos de alfabetização e letramento}

$\mathrm{Na}$ perspectiva da alfabetização e do letramento, trazemos, nesta seção, reflexões sobre algumas políticas públicas referentes à educação com o objetivo de melhor compreender como tais políticas permeiam os processos de alfabetização no Brasil. Também buscamos refletir sobre os desafios envolvidos na sua implementação por meio da política do Ensino Fundamental de nove anos (BRASIL, 2007), que estabelece prazo até os oito anos de idade para a alfabetização das crianças, até o Pacto Nacional pela Alfabetização na Idade Certa (BRASIL, 2012). Com base nas 
concepções dessas políticas, buscamos relacioná-las com a política de implementação do Projeto APD, objeto de análise neste artigo.

Nas últimas décadas, o Ensino Fundamental no Brasil passou por uma série de mudanças. Um dos encaminhamentos por parte do Estado para resolver o problema da qualidade da educação e do fracasso escolar foi a criação da Lei Federal no 11.274/2006, que amplia o tempo de duração do Ensino Fundamental para nove anos.

Atualmente, a educação mineira é direcionada pela Resolução SEE/MG no 2.197/2012, que propõe que os Ciclos da Alfabetização e Complementar devem garantir o princípio da continuidade da aprendizagem dos alunos sem interrupção, com foco na alfabetização e no letramento.

Outras ações fizeram-se necessárias em nível nacional na tentativa de garantir o direito à alfabetização na idade certa. Para auxiliar no desenvolvimento do Ciclo da Alfabetização, foi implantado o Programa Nacional Alfabetização na Idade Certa (Pnaic).

Para alcançar os objetivos propostos, o Pnaic foi firmado em quatro eixos de sustentação (formação continuada presencial; material didático; avaliações; gestão, mobilização e controle social). O Pnaic foi desenvolvido de 2013 a 2018, e ao longo das suas edições buscou dar ênfase aos estudos de Alfabetização - Língua Portuguesa em interface com os demais conteúdos escolares, da Alfabetização Matemática, da interdisciplinaridade e, por último, na edição 2017/2018, também contemplando a Educação Infantil.

A Avaliação Nacional da Alfabetização (ANA) é uma das justificativas para a implementação do Pnaic. ANA é uma avaliação em larga escala concebida com o propósito de que, por meio dos seus resultados, fosse possível concorrer para a melhoria da qualidade de ensino e redução das desigualdades. Contudo, os indicadores de desempenho medidos por meio de tal avaliação sinalizam uma quantidade significativa de crianças com níveis insuficientes de aprendizagem (especialmente em leitura e matemática), o que acaba por acionar a preocupação em torno do processo de alfabetização e, consequentemente, de todas as etapas da Educação Básica.

Dos alunos avaliados pela ANA em 2016, 55\% apresentam níveis de leitura insuficientes. Mais da metade dos alunos não apresenta resultados satisfatórios, o que nos leva a confirmar, mais uma vez, que a 
maioria dos alunos está chegando ao 4ํㅡㅁ ano de escolaridade sem consolidar as habilidades básicas inerentes ao processo de alfabetização e letramento. Sabemos que avaliações em larga escala não são a única forma de aferição das práticas de leitura e escrita, mas no cenário educacional atual constituise uma das ferramentas usadas.

Diante desses dados é que nos importa tratar da implementação de políticas públicas que possam ajudar a sanar essas dificuldades enfrentadas pelos alunos, como é o caso do projeto APD, implantado em Minas Gerais nas 47 Superintendências Regionais de Ensino, destinado aos estudantes inseridos nas turmas de 4음 ao ano do Ensino Fundamental, com ou sem distorção idade/ano de escolaridade e que ainda não dominam o processo de alfabetização e letramento (MINAS GERAIS, 2016).

O projeto APD é baseado na Lei de Diretrizes e Bases da Educação Nacional - LDB), que orienta e enfatiza a importância da oferta de novas oportunidades de aprendizagem sempre que o estudante apresentar dificuldades, sobretudo nos processos de leitura, de produção textual oral e escrita e de cálculos matemáticos simples.

Os critérios adotados no projeto consideram a análise do processo de apropriação do sistema de escrita alfabética, dificuldades relacionadas à leitura e à produção de textos, dificuldades quanto aos aspectos básicos da ortografia.

As escolas contempladas com o projeto APD têm direito à contratação de um profissional específico (alfabetizador) para o desenvolvimento das ações. Nas demais escolas (não contempladas), na Superintendência de Ensino em que se deu esta pesquisa, esse trabalho é exercido pelo Peub, concomitantemente com as outras atribuições do cargo. Cada escola tem autonomia para determinar a carga horária que será destinada ao desenvolvimento das ações de intervenção pedagógica. Há de se ressaltar que o cargo de Peub não exige experiência em alfabetização, podendo ser exercido por qualquer professor licenciado em qualquer componente curricular. Por isso, sabemos que, muitas vezes, não dominam os saberes desejáveis para as práticas de se alfabetizar letrando, sendo necessário adequarem o trabalho a esse contexto.

Conforme documento orientador do projeto, a metodologia utilizada deve considerar aspectos fundamentais de Língua Portuguesa e Matemática que possibilitam a compreensão e o entendimento do mundo nos aspectos práticos da vida cotidiana. Tais aspectos se reafirmam na 
proposta da Base Nacional Comum Curricular (BNCC), que propõe que a construção do conhecimento não seja disciplinar e fragmentada, ao contrário, ressalta a importância do protagonismo do estudante em sua aprendizagem e na construção de seu projeto de vida (BRASIL, 2017, p. $15)$.

A BNCC destaca também a necessidade de se aprofundar as experiências com as modalidades oral e escrita já iniciadas no âmbito familiar e na Educação Infantil e reforça a proposta do Projeto APD, ao definir as aprendizagens essenciais que todos os estudantes devem desenvolver, garantindo, dessa maneira, seus direitos de aprendizagem.

Percebe-se, pois, que as políticas públicas brevemente apresentadas se articulam com o objetivo de garantir os direitos de aprendizagem dos estudantes e o projeto APD, apresentado mais detalhadamente na seção 3.1, contribuindo para que tal garantia de aprendizagem exista, de fato.

\subsection{Desenvolvimento do projeto APD e as dificuldades em leitura e escrita}

A Superintendência Regional de Ensino em que se originou este estudo atende a 27 escolas que ofertam o Ensino fundamental. Em 2016, ano de implantação do Projeto APD, apenas três escolas foram contempladas com o projeto. Em 2017 e 2018, cinco escolas foram contempladas.

Como evidências, esta pesquisa aborda os dados levantados nesta regional, que apresenta um número elevado de alunos com dificuldades de aprendizagem (de um total de 7.324 matriculados, 807 alunos apresentam dificuldades de aprendizagem), ${ }^{6}$ o que corresponde à $11,02 \%$ do total de estudantes.

Assim, considerando o total de 807 alunos identificados com dificuldades, apenas 195 eram atendidos individualmente por um professor alfabetizador contratado especificamente para esse fim nas cinco escolas contempladas. Foi elaborada para as demais 22 escolas não contempladas, com um total de 612 alunos, uma orientação conjunta para que todas desenvolvessem o projeto. Dessa forma, definiu-se que os 612 alunos

\footnotetext{
${ }^{6}$ Conforme resultados de avaliações diagnósticas das escolas constantes no arquivo pedagógico da regional pesquisada.
} 
contariam com o apoio dos Professores para Ensino do Uso da Biblioteca, que buscariam desenvolver as mesmas ações do projeto, adequando para a realidade de cada unidade escolar de acordo com suas especificidades.

Para fins desta pesquisa, delimitou-se para análise nove escolas estaduais que atendem ao Ensino Fundamental no Município Sede da Superintendência Regional de Ensino. As escolas são identificadas com nomes de escritores brasileiros, ${ }^{7}$ sendo a Escola Estadual Manuel Bandeira e a Escola Estadual Cora Coralina (primeiras do quadro a seguir) escolas contempladas no projeto APD, e as demais são escolas não contempladas.

A tabela 1, representado anteriormente, apresenta as escolas da sede da Superintendência Regional de Ensino em questão, evidenciando que dos 318 alunos dessas escolas 87 estão inseridos nas duas escolas contempladas com o projeto, ${ }^{8}$ ou seja, estão sendo atendidos diretamente por um professor contratado para esse fim, enquanto 231 alunos das demais escolas estão sendo atendidos pelos Peub das respectivas escolas.

Para identificar os níveis nos quais os alunos se encontravam, as escolas aplicaram avaliações diagnósticas de acordo com as especificidades de cada uma, mas em consonância com as habilidades de acordo com o Currículo Básico Comum (CBC) do Estado de Minas Gerais. Com base nessas avaliações, foi constatado que muitos alunos não haviam completado o processo de alfabetização, pois apresentavam defasagens muito acentuadas em leitura e escrita; muitos sequer chegariam a estar minimamente alfabetizados.

Quanto à leitura, o projeto APD trabalha de acordo com as orientações de seu Documento Orientador, com uma classificação própria, em que os estudantes são agrupados em quatro níveis de leitura: não lê, lê silabando, lê sem fluência e lê com fluência. Nas nove escolas analisadas, temos 31 alunos no primeiro nível, ou seja, que "não leem". Temos ainda 86 alunos que "leem silabando", 102 que "leem sem fluência" e apenas 99 estão "lendo com fluência". Considerando que estamos falando de alunos do 4ํaㅇ ao ano, a situação apresenta-se bastante crítica.

\footnotetext{
${ }^{7}$ Nomes fictícios a fim de preservar a identidade das escolas.

${ }^{8}$ Escolas identificadas na Tabela 1 com o símbolo *
} 
Tais constatações nos levam também a refletir sobre o processo de alfabetização, corroborando Magda Soares (2018) quando ela argumenta que letrar é mais que alfabetizar: é ensinar a ler e a escrever dentro de um contexto em que a leitura e a escrita tenham sentido e façam parte da vidado aluno. Paulo Freire já sustentava essa ideia, ao defender que uma leitura realizada no sentido de memorizá-la nem é leitura real, nem resulta no conhecimento do objeto do qual o texto fala (FREIRE, 1989).

Tabela 19. Quantitativo de alunos atendidos no Projeto APD por ano de escolaridade

\begin{tabular}{|c|c|c|c|c|c|c|c|}
\hline \multirow{2}{*}{$\begin{array}{l}\text { Escolas Estaduais da Sede } \\
\text { da Regional de Ensino }\end{array}$} & \multicolumn{6}{|c|}{$\begin{array}{l}\text { Quantitativo de alunos atendidos no projeto APD por } \\
\text { ano de escolaridade }\end{array}$} & \multirow{2}{*}{$\begin{array}{r}\text { Total de alunos no APD } \\
\text { por escola }\end{array}$} \\
\hline & $4^{\circ}$ ano & $5^{\circ}$ ano & $6^{\circ}$ ano & $7^{\circ}$ ano & $8^{\circ}$ ano & $9^{\circ}$ ano & \\
\hline E.E. Cora Coralina* & 10 & 10 & 10 & 6 & 5 & & 41 \\
\hline E.E. Aluísio Azevedo & 9 & 7 & 5 & 3 & 2 & 5 & 31 \\
\hline E.E. Lima Barreto & 6 & 10 & 6 & 6 & 6 & 2 & 36 \\
\hline E.E. Érico Veríssimo & 0 & 0 & 4 & 6 & 3 & 1 & 14 \\
\hline E.E. Adélia Prado & 6 & 6 & 6 & 2 & 2 & 7 & 29 \\
\hline E.E. Lygia Fagundes Telles & 10 & 9 & 5 & 3 & 4 & 1 & 32 \\
\hline Total geral de alunos & 80 & 83 & 49 & 37 & 39 & 30 & 318 \\
\hline
\end{tabular}

Fonte: arquivo SRE (2018)

${ }^{9}$ Legenda: * escolas contempladas com o Projeto APD 
Quanto à leitura, o projeto APD trabalha de acordo com as orientações de seu Documento Orientador, com uma classificação própria, em que os estudantes são agrupados em quatro níveis de leitura: não lê, lê silabando, lê sem fluência e lê com fluência. Nas nove escolas analisadas, temos 31 alunos no primeiro nível, ou seja, que "não leem". Temos ainda 86 alunos que "leem silabando", 102 que "leem sem fluência" e apenas 99 estão "lendo com fluência". Considerando que estamos falando de alunos do 4ํa ao 9a ano, a situação apresenta-se bastante crítica.

Tais constatações nos levam também a refletir sobre o processo de alfabetização, corroborando Magda Soares (2018) quando ela argumenta que letrar é mais que alfabetizar: é ensinar a ler e a escrever dentro de um contexto em que a leitura e a escrita tenham sentido e façam parte da vida do aluno. Paulo Freire já sustentava essa ideia, ao defender que uma leitura realizada no sentido de memorizá-la nem é leitura real, nem resulta no conhecimento do objeto do qual o texto fala (FREIRE, 1989).

Assim, partindo dos dados evidenciados anteriormente, buscamos discutir a alfabetização como direito de todos, ancoradas na discussão teórica acerca do tema alfabetização e letramento.

\section{Delineamento metodológico}

Esta investigação foi realizada com a finalidade de gerar dados com os quais pudéssemos mapear os desafios e as perspectivas do Projeto APD com alunos do $4^{\circ}$ ao $9^{\circ}$ ano do Ensino Fundamental, na perspectiva dos professores participantes. Por meio da análise de dados esperamos refletir sobre maneiras de se minimizar as dificuldades de alfabetização e letramento enfrentadas pelos alunos atendidos pelo Projeto. Para tal, optamos pela abordagem qualitativa de pesquisa, cuja coleta de dados se deu por meio do grupo focal.

As abordagens qualitativas de pesquisa fundamentam-se em uma perspectiva que concebe o conhecimento como um processo socialmente construído pelos sujeitos nas suas interações cotidianas, enquanto atuam na realidade, transformando-a e sendo por ela transformados. Dessa forma, se a visão de realidade é construída pelos sujeitos, nas interações sociais vivenciadas em seu ambiente de trabalho, de lazer, na família, torna-se 
fundamental uma aproximação do pesquisador dessas situações (ANDRÉ, 2013).

Dessa forma, corroboramos André (2013) ao refletirmos que nosso estudo se assemelha a um estudo de caso instrumental, no qual o caso não é uma situação concreta, mas uma questão mais ampla, como, por exemplo, a incorporação de uma política no cotidiano escolar. Assim, escolhemos algumas escolas que servirão de base para investigar como essa política é desenvolvida pelos atores escolares.

Para realizarmos a pesquisa, optamos como instrumento de coleta de dados a técnica de grupo focal, que, conforme Gatti (2005, p. 7), pode ser definida como "um conjunto de pessoas selecionadas e reunidas ${ }^{10}$ por pesquisadores para discutir e comentar um tema, que é objeto de pesquisa, a partir de sua experiência pessoal".

Foi realizada uma reunião de grupo focal com a participação dos profissionais envolvidos no projeto: professores específicos do Projeto APD e Professores para Ensino e Uso de Biblioteca das escolas não contempladas. O encontro aconteceu no dia 21 de novembro de 2018; das nove escolas selecionadas e dos nove profissionais envolvidos, estiveram presentes oito escolas e oito profissionais.

$\mathrm{Na}$ reunião, os participantes responderam a nove questões previamente elaboradas para a discussão. Este momento foi filmado em vídeo e gravado em áudio. Foi realizada a transcrição de todas as falas dos participantes que responderam às perguntas específicas sobre a logística e o desenvolvimento do projeto, bem como sobre as dificuldades enfrentadas no processo de alfabetização e letramento dos alunos atendidos. ${ }^{11}$

Tomando por base as falas das participantes na reunião dos grupos focais, foi possível delimitar quatro eixos de análise que serão apresentados a seguir.

\footnotetext{
${ }^{10}$ Todos os participantes assinaram o TCLE e tiveram esclarecimentos sobre os objetivos da pesquisa.

11 ara detalhamento e consulta ao roteiro sugerimos a leitura da dissertação no link: http://mestrado.caedufjf.net/desafios-e-perspectivas-do-projeto-acompanhamentopedagogico-diferenciado-apd-para-alunos-do-4o-ao-9o-ano-do-ensinofundamental/
} 
Alfabetização e letramento nos processos de ensino e aprendizagem...

\section{Análise de dados}

A análise foi realizada com base no material coletado no grupo focal à luz das concepções teóricas dos autores que abordam questões de alfabetização e letramento e outros que direta ou indiretamente estejam ligados às questões apresentadas. Para melhor compreensão das questões discutidas nas reuniões realizadas, organizamos o Quadro 1 para apresentar os eixos de análise que delimitamos.

Quadro 1. Eixos de análise e objetivos

\begin{tabular}{|c|l|l|}
\hline Ordem & \multicolumn{1}{|c|}{ Eixos de análise } & \multicolumn{1}{c|}{ Objetivos } \\
\hline 1 & $\begin{array}{l}\text { Operacionalização e logística do } \\
\text { projeto APD. }\end{array}$ & $\begin{array}{l}\text { Identificar as dificuldades enfrentadas } \\
\text { pelas escolas e pelos profissionais na } \\
\text { implementação do projeto. }\end{array}$ \\
\hline 2 & $\begin{array}{l}\text { Avaliação, planejamento e } \\
\text { materiais pedagógicos utilizados } \\
\text { no projeto APD. }\end{array}$ & $\begin{array}{l}\text { Identificar as diversas metodologias de } \\
\text { avaliação e planejamento no } \\
\text { desenvolvimento do projeto. }\end{array}$ \\
\hline 3 & $\begin{array}{l}\text { Níveis de } \\
\text { desenvolvimento e avanço dos } \\
\text { alunos. }\end{array}$ & $\begin{array}{l}\text { Mapear os diversos níveis dos alunos, } \\
\text { bem como o desenvolvimento de } \\
\text { atividades que promovam o avanço } \\
\text { desses níveis. }\end{array}$ \\
\hline 4 & $\begin{array}{l}\text { Facilitadores de } \\
\text { aprendizagem/melhoria no } \\
\text { processo ensino/aprendizagem. }\end{array}$ & $\begin{array}{l}\text { Analisar as práticas pedagógicas } \\
\text { realizadas nas escolas que facilitam o } \\
\text { processo ensino-aprendizagem. }\end{array}$ \\
\hline
\end{tabular}

Fonte: elaboração das autoras

A seguir, apresentamos as discussões de cada eixo de análise de acordo com a pesquisa realizada, trazendo os fatores relacionados ao contexto escolar desde a operacionalização até os fatores que influenciam direta ou indiretamente na melhoria do processo ensino/aprendizagem dos alunos atendidos no projeto.

\section{Eixo 1: Operacionalização e logística do projeto APD}

Neste eixo, apresentamos as diferentes perspectivas das escolas envolvidas quanto à operacionalização/implementação do projeto APD. Foi perguntado às professoras sobre a questão do estabelecimento de horários para desenvolvimento das ações, sobre adequação/existência de espaço 
físico, periodicidade no desenvolvimento do projeto e envolvimento da gestão escolar e demais atores da escola, bem como os desafios e as dificuldades encontradas.

De acordo com os relatos de algumas professoras, há problemas quanto ao espaço físico específico para atendimento ao projeto e à alta rotatividade de alunos:

\section{Excerto 1.}

[...] o problema maior que eu tive foi espaço. Eu cheguei e a diretora falou: não tem uma sala, já levei os alunos para a biblioteca, para o corredor, para a sala de multimídia, quadra da escola... Enfim... O problema maior é o espaço. Outra dificuldade é assim: no mesmo tempo que estão na escola, eles mudam, ficam um tempo fora, depois voltam de novo. Teve alunos que ficaram dois meses e depois voltou, aí o trabalho volta à estaca zero (PROFESSORA B, E. C. CORALINA).

Sobre a questão do espaço físico, entendemos que o problema precisa ser discutido com a direção da escola. Quando uma escola é contemplada com o projeto ela está entre os critérios definidos pela SEE/MG, ou seja, apresenta baixos índices nos resultados das avaliações externas do Sistema Mineiro de Avaliação e Equidade da Educação Pública (Simave), deve estar localizada em área de vulnerabilidade social e possuir um grande número de alunos que apresentam dificuldades no desenvolvimento da aprendizagem, necessitando de maior empenho da equipe gestora em receber e desenvolver o projeto visando à melhoria de sua unidade escolar.

A sobrecarga de trabalho também foi citada como impedimento para o cumprimento de horários estabelecidos para o projeto:

\section{Excerto 2.}

[...] nunca dava tempo, chegava hora de eu ir atender esses alunos, um professor faltou, uma coisa aqui, outra ali e eu tinha que ir pra sala; na terça da mesma forma, e assim foi indo... Foram poucas vezes que fui para sala, então tive muita dificuldade (PROFESSORA H, E.E. L. FAGUNDES). 
Alfabetização e letramento nos processos de ensino e aprendizagem...

Assim, constatamos, de acordo com os relatos, que não há continuidade do trabalho com o projeto APD, sendo, muitas vezes, outras demandas consideradas prioridades na escola em detrimento do acompanhamento pedagógico que realizam.

\section{Eixo 2: Avaliação, planejamento e materiais pedagógicos}

Neste eixo, apresentamos as perguntas realizadas no grupo focal com o objetivo de conhecer o planejamento e os tipos de avaliações, bem como os materiais pedagógicos utilizados nas diferentes escolas.

Iniciamos investigando como é realizada a avaliação dos alunos e o planejamento do trabalho no projeto APD. Percebemos, pelos relatos das participantes, que não existe um modelo padrão nem de avaliação, nem de planejamento, pois cada escola e cada profissional escolhem uma forma para avaliar e planejar seu trabalho.

Identificamos também que a avaliação não foi o foco inicial do projeto. Cada escola e cada professora usaram uma metodologia de trabalho sem se preocupar com o diagnóstico inicial dos alunos, o que pode ser evidenciado nos trechos dos relatos de três professoras:

\section{Excertos 3.}

Nós fizemos uma avaliação diagnóstica só de leitura, na avaliação de processo. Eu avalio em duplas, a questão da leitura com eles é bem por percepção com escrita e produção de textos (PROFESSORA C., E.E. A. AZEVEDO).

$\mathrm{Na}$ escola usamos o método das palavras geradoras, de Paulo Freire. Usei o mesmo método em todas as avaliações. Eu coloquei no portfólio as avaliações que usei (PROFESSORA G., E. E. A. PRADO).

Eu trabalhei com diagnóstico oral, assim cobrando deles na hora que eu comecei o projeto. Daí eu fui adaptando as perguntas, as avaliações para cada um; se ele superou aquelas dificuldades ou não (PROFESSORA H., E. E. L. FAGUNDES).

Com base nos relatos podemos inferir que muitas escolas realizaram a "avaliação diagnóstica" somente para cumprir "protocolo", sem nenhuma articulação com o planejamento de atividades para sanar as dificuldades encontradas. A respeito do planejamento, identificamos que, 
tal como acontece com as avaliações diagnósticas, a maioria das escolas trabalha no que poderíamos chamar de "improviso". Muitas atribuem a falta de planejamento a vários fatores, conforme podemos observar nos trechos a seguir:

\section{Excerto 4.}

Eu fiz o planejamento, mas eu tive dificuldade, eu não tive ajuda para desenvolver. A ajuda que tive foi dos materiais das professoras eventuais que me passaram um trabalho que elas já tinham feito, e aí eu escolhi classificar os alunos por níveis e trabalhei com eles de uma forma geral, mas em cima dos níveis. Então o planejamento foi por nível, não individual (PROFESSORA C., E. E. A. AZEVEDO).

Outra professora relata que decidia de última hora o que iria trabalhar, sem nenhuma base em avaliações anteriores:

\section{Excerto 5.}

Eu também não fiz planejamento... fiz o meu, por exemplo, eu decidia assim: essa semana eu vou trabalhar isso; vou trabalhar em cima dessas dificuldades deles, é adição, é multiplicação... é um texto... vou trabalhar em cima dessas dificuldades, não fiz um planejamento, tipo um plano de aula mesmo (PROFESSORA H., E. E. L. FAGUNDES).

Em conformidade com Batista (2005b), consideramos que o planejamento tem uma dimensão fundamental do trabalho pedagógico, porque permite, aos professores e à escola, controlar os resultados e a consecução das finalidades deste trabalho. $O$ autor defende que a autonomia da escola depende de planejamento, seu desenvolvimento e avaliação do processo, assim pode (re)definir suas metas e meios. Dessa maneira, entendemos que quando uma escola e seus professores renunciam ao planejamento estão abrindo mão de sua autonomia, do controle de seu trabalho e do desenvolvimento adequado de seus alunos.

Identificamos, ainda, que determinadas escolas contavam apenas com os Peub e que alguns desses professores não tinham formação na área de alfabetização, sendo um obstáculo para o desenvolvimento do projeto. Os Peub, conforme explicado anteriormente, são professores responsáveis 
por atividades na biblioteca da escola, não sendo obrigatória a formação ou experiência em alfabetização.

Quanto ao uso e à adaptação de materiais, mesmo com as dificuldades relatadas constatamos que muitos professores desenvolvem diferentes metodologias em busca de atender as especificidades dos alunos do projeto. Observamos na pesquisa que cada professora trabalha com base em uma concepção de alfabetização, aplicando métodos e estratégias variadas de acordo com o que percebe que funciona com o público que atende. Por exemplo, a professora A relata que realiza trabalhos concretos com seus alunos. Dentre esses trabalhos, destaca o mercadinho, que ela considerou a prática que mais deu resultados com a turma, conforme podemos constatar na sua fala:

\section{Excerto 6.}

Eu trabalhei de forma concreta com eles. Um dos destaques foi o mercadinho, todos queriam ir, usei as quatro operações, e com o mercadinho deu para trabalhar em todas as áreas, desde a leitura, a escrita, as operações simples, as mais complexas, aquelas que têm vírgula, né? O troco... Tem aluno que não lê nada, mas ele sabe dar troco, ele corrige um aluno que é maior, que era pra saber, e ele sabe... Então a prática que eu destaco foi o mercadinho (PROFESSORA A., M. BANDEIRA).

Para concluirmos este eixo, constatamos que mesmo com as dificuldades apontadas na realização das avaliações, nos planejamentos, na adaptação de materiais, no pouco tempo disponível, ainda assim as professoras buscam trabalhar estratégias variadas a fim de despertar o interesse de seus alunos, tendo como objetivo facilitar seu desenvolvimento no processo de alfabetização e letramento. Por analogia, aqui trazemos o argumento defendido por Kleiman (2010, p. 3): "A partir do momento que o letramento do aluno é definido como objetivo de ação pedagógica, o movimento será da prática social para o conteúdo, nunca ao contrário, se o letramento do aluno for objetivo da ação pedagógica".

\section{Eixo 3: Níveis de desenvolvimento e avanço dos alunos}

Com base nos relatos, neste eixo, constatamos que os alunos do projeto APD se encontram em variados níveis de alfabetização, desde aqueles que não conhecem o alfabeto até os que estão no nível alfabético, 
em que compreendem o sistema de escrita, mas ainda não dominam as convenções ortográficas; por exemplo, trocam a letra " $\mathrm{g}$ " por “ $\mathrm{j}$ ”.

Algumas professoras classificam os alunos no nível alfabético, porém os relatos não evidenciam claramente essa identificação, mas, sim, sua evolução, conforme podemos observar em alguns trechos destacados:

\begin{abstract}
Excerto 7.
[...] eu escolhi classificar os alunos por níveis e trabalhei com eles de uma forma geral, mas em cima dos níveis. [...] vejo que eles melhoraram o nível de escrita, de fluência na leitura e na interpretação; a produção de textos eu tive pouco tempo para trabalhar com eles, eles demoram mais na questão das ideias... assim a produção cognitiva deles melhorou, mas quando vai para o papel para produzir eles relacionam muito a escrita à fala. Constroem a ideia, mas só eles lendo para eu entender (PROFESSORA C., E. E. A. AZEVEDO).
\end{abstract}

No mesmo sentido, outras professoras também argumentam que seus alunos avançaram na leitura, mas estão insuficientes na escrita:

\title{
Excertos 8.
}

$\mathrm{Na}$ nossa escola, o avanço da escrita ficou um pouco a desejar, principalmente as palavras mais complexas, né? Mas assim na fluência da leitura melhorou bastante (PROFESSORA D., E. E. L. BARRETO).

[...] assim o nível de leitura deles, desenvolveram bastante, mas na escrita, não; geralmente a gente faz uma ligação entre a escrita e a leitura, e eles estão desenvolvendo mais na leitura (PROFESSORA G., E. E. A. PRADO).

Dessa forma, percebemos várias estratégias utilizadas com o objetivo de facilitar o trabalho e proporcionar uma maior e melhor aproximação com os alunos. No entanto, constatamos também que os alunos estão avançando na leitura, mas ainda com dificuldades na escrita. Entendemos, porém, que, na perspectiva da alfabetização e do letramento, os processos de leitura e escrita são indissociáveis.

A professora $\mathrm{B}$, que atende 41 alunos específicos do projeto, ressalta que há grandes dificuldades dos alunos na escrita e leitura: 


\section{Excerto 9.}

Os alunos são na maioria do nível silábico-alfabético, alguns no alfabético, mas com grandes dificuldades em reconhecer sílabas, muitos não sabiam o que era uma sílaba, tivemos essa dificuldade, troca de letras, de fonemas, o ensinar a LER mesmo, tivemos que ensinar para eles do início. [...] A escrita, as sílabas complexas têm que ser mais trabalhadas, porque eu acho que o professor poderia cobrar mais, né? Com ele na sala de aula, porque às vezes você pede assim: lê o que você escreveu, aí ele diz: - Ah, está faltando um "n"! Então ele percebe que falta alguma coisa. Se trabalhar mais essa parte, não só a gente trabalhar, mas na sala de aula, seria melhor, né? (PROFESSORA B., E. E. CORA CORALINA).

Identificamos, no relato da professora $\mathrm{B}$, que a maioria de seus alunos se encontra no nível silábico-alfabético. Nesse nível, os estudantes tanto podem representar sílabas completas como representá-las por uma letra só, o que pode justificar a dificuldade dos alunos em identificar o que é a sílaba e a troca de letras relatados pela professora. Percebemos, pela experiência de coordenação do projeto, que os alunos das escolas contempladas apresentam níveis mais baixos de desenvolvimento do que os das escolas não contempladas - o que se justifica pelos critérios de seleção das escolas destacados no Documento Orientador: são selecionadas aquelas escolas consideradas com maior número de alunos com notas abaixo do esperado nas avaliações externas e localizadas em áreas de vulnerabilidade social (MINAS GERAIS, 2018).

Destacamos, ainda neste eixo, a complexidade que envolve os processos de alfabetização e letramento, a qual indica prementes mudanças nas práticas que levam os alunos a se apropriarem da linguagem, de forma a possibilitar-lhes uma dinâmica dialética, conforme destaca Paulo Freire (2003), de que o verdadeiro letramento implica a percepção das partes entre o texto e o contexto.

\section{Eixo 4: Facilitadores de aprendizagem/melhoria no processo ensino aprendizagem}

De maneira geral, todas as escolas envolvidas realizaram ações para o desenvolvimento do projeto. As professoras relatam atividades diversas de acordo com a realidade de cada escola e ressaltam como pontos 
positivos a melhora da autoestima dos alunos, a motivação, os avanços na leitura, na escrita e na interpretação. Salientam também o uso da ludicidade e das tecnologias como facilitadores no desenvolvimento dos alunos. No entanto, de consenso, a opinião é de que o projeto deveria acontecer em todas as escolas e iniciar mais cedo (no ciclo da alfabetização).

\section{Excerto 10.}

Eu acho que ponto positivo é a gente alfabetizar o aluno, porque o aluno quando chega lá pra gente, a maioria deles, eu acho assim, principalmente os de $6^{0}$ ano, eles não são alfabetizados, então o ponto positivo seria ter êxito na alfabetização desse aluno. E também eu acho que o projeto APD deveria acontecer a partir do 3o ano, né? Deveria descer um ano lá de cima e começar do início que eu acho que seria melhor ainda (PROFESSORA G., E. E. A. PRADO).

Assim como a professora $\mathrm{G}$, a professora A também concorda que o projeto deveria iniciar mais cedo e acrescenta: "[...] acho que tinha que ter em todas as escolas, mesmo que seja uma taxa mínima de alunos com dificuldades, tem que colocar sim”.

A questão da motivação e da melhoria da autoestima dos alunos foi um ponto bastante discutido entre as participantes, que concordam, de maneira geral, que o projeto ajuda a resgatar a autoestima daqueles alunos que se sentem segregados do processo tradicional nas suas turmas de origem. Nos relatos das participantes, foi enfatizado que os alunos se sentem mais à vontade com os colegas, sentem-se mais seguros para perguntar, para se ajudarem mutuamente, o que pode ser confirmado com o relato da professora da E. E. Lima Barreto: “[...] eles estão ali dividindo entre eles a mesma dificuldade, então ninguém se acha melhor do que ninguém, então eu achei que a autoestima deles, assim, cresceu" (PROFESSORA D., E. E. LIMA BARRETO).

Outro ponto destacado foi a questão da afetividade professor-aluno. As participantes concordam que é essencial estabelecer um bom convívio e cativar o aluno. Com o estabelecimento desse vínculo, os alunos sentem-se mais à vontade para perguntar e sanar suas dúvidas por estarem apenas com os colegas do mesmo nível e com a professora na qual eles sentem confiança. 
Percebemos também, no desenvolvimento do projeto APD, que os professores usam diferentes estratégias que promovam o letramento para desenvolver as habilidades necessárias nos alunos e inseri-los na sociedade.

Assim, observamos que as professoras participantes do projeto, mesmo diante das dificuldades relatadas, têm buscado caminhos para atender os diferentes grupos de alunos e oferecem sugestões de como poderia haver melhorias no processo. Essas proposições foram transformadas em um Plano de Ação Educacional, que será objeto de trabalhos futuros.

\section{Considerações finais}

Apoiadas na perspectiva de que o desenvolvimento em leitura e escrita possibilita aos sujeitos uma formação crítica e cidadã, além de promover a aquisição de novos conhecimentos, este artigo trouxe reflexões sobre questões relacionadas ao Projeto APD, que busca contribuir com os processos de alfabetização e de letramento de alunos com dificuldades em leitura e escrita no Ensino Fundamental.

Temos ciência de que as condições disponíveis para a implementação do projeto são diversas, mas é importante buscar estratégias que garantam o desenvolvimento dos estudantes, respeitando as diferenças e o ritmo de cada um. É necessária uma articulação das instituições educacionais a fim de sustentar uma formação positiva, assegurando igualdade e equidade no processo de ensino-aprendizagem de todas as unidades escolares.

Entendemos ainda que o fracasso escolar, subentendido na perspectiva do Projeto APD, deve ser tratado com cuidado, sendo necessário um olhar amplo a todas as esferas que envolvem o aluno e o contexto em que o fracasso acontece.

Podemos considerar que a alfabetização depende de diferentes características e de diferentes culturas e que, por conseguinte, o sucesso ou o fracasso de uma criança vai depender do estágio de compreensão da escrita em que ela se encontra, além de considerar ainda aspectos sociais e políticos que condicionam a aprendizagem.

Com base no grupo focal realizado com os professores, constatamos que trabalhar com alunos não alfabetizados é um grande 
desafio: há a necessidade de um maior planejamento do projeto que envolva não apenas o professor, mas a gestão da escola como um todo, dando condições adequadas de atendimento aos estudantes. Destacamos, também, a importância da identificação do nível de alfabetização de cada aluno para um direcionamento mais preciso das atividades. Por fim, os professores ressaltam um aspecto muito importante: o projeto proporciona um fortalecimento na relação aluno-professor, trazendo um sentimento de maior confiança à criança.

Nesse contexto, corroboramos a ideia de Charlot (2011) de que "o 'fracasso escolar' não existe; o que existe são situações de fracasso, histórias escolares que terminam mal", e é esse viés defendido pela proposta do projeto APD: buscar estratégias para garantir os direitos de aprendizagem de todos os estudantes.

\section{Referências}

ANDRÉ, M. O que é um estudo de caso qualitativo em educação? Educação e Contemporaneidade - Revista FAEEBA, v. 22, n. 40, p. 95103, jul./dez, 2013.

BATISTA, A. et al. Capacidades da alfabetização. Belo Horizonte: Ceale/UFMG, 2005a.

BATISTA, A. et al. Planejamento da alfabetização. Belo Horizonte: UFMG, 2005b.

BRASIL. Ministério da Educação. Base Nacional Comum Curricular. Disponível em:

< http://basenacionalcomum.mec.gov.br/abase>. Acesso em: 19 ago. 2018.

BRASIL. Ministério da Educação. Pacto Nacional pela Alfabetização na Idade Certa. Disponível em: 〈http://pacto.mec.gov.br/historico-pnaic〉. Acesso em: 28 mar. 2018. 
Alfabetização e letramento nos processos de ensino e aprendizagem...

BRASIL. Ministério da Educação. Programa Mais Alfabetização. Manual Operacional do Sistema de Orientação Pedagógica e Monitoramento. Brasília: MEC, 2018.

CHARLOT, B. Vídeo: existe o fracasso escolar? Publicado em: 30 jun. 2011. Disponível em: <https://www.youtube.com/watch?v=1HUJQld>. Acesso em: 28 abr. 2018.

CHARLOT, B. A psicogênese da língua escrita. Porto Alegre: Artes Médicas, 1986.

FERREIRO, E. Alfabetização em processo. 11. ed. São Paulo: Cortez, 1996.

FREIRE, P. A importância do ato de ler: em três artigos que se completam. 15. ed. São Paulo: Cortez, 1989.

GATTI, B. Grupo focal na pesquisa em Ciências Sociais e Humanas. Série Pesquisa em Educação. v. 10. Brasília, 2005.

KLEIMAN, A. (Org.). Os significados do letramento: uma nova perspectiva sobre a prática social da escrita. Campinas: Mercado das Letras, 1995.

KLEIMAN, A. (Org.). Trajetórias de acesso ao mundo da escrita: relevância das práticas não escolares de letramento para o letramento escolar. Perspectiva, Florianópolis, 2010.

MARINHO, M. A escrita nas práticas de letramento acadêmico. Revista Brasileira de Linguística Aplicada, Belo Horizonte, v. 1, n. 2, p. 363-386, ago. 2010.

MINAS GERAIS. Secretaria Estadual de Educação. Resolução SEE n. 2.197, 2012. 
MINAS GERAIS. Secretaria Estadual de Educação de Minas Gerais. Documento Orientador Projeto Acompanhamento Pedagógico Diferenciado, 2017.

MINAS GERAIS. Secretaria Estadual de Educação de Minas Gerais. Documento Orientador Projeto Acompanhamento Pedagógico Diferenciado, 2018.

SOARES, M. Letramento e alfabetização: as muitas facetas. Revista Brasileira de Educação, UFMG, n. 25, 2004.

SOARES, M. Letramento: um tema em três gêneros.Belo Horizonte: Autêntica, 1998.

SOARES, M. Alfabetização: a questão dos métodos. São Paulo: Contexto, 2018.

SOARES, M. Práticas de letramento e implicações para a pesquisa e para políticas de alfabetização e letramento. In: MARINHO; CARVALHO (Org.). Cultura escrita e letramento. Belo Horizonte: Editora UFMG, 2010 .

STREET. Letramentos sociais: abordagens críticas do letramento no desenvolvimento, na etnografia e na educação. São Paulo: Parábola, 2014.

Recebido em: 30/07/2020

Aceito em: 26/11/2020

Title: Analysis of the Differentiated Monitoring Project for Students with Learning Disabilities in reading and writing in public schools in Minas Gerais 